\title{
Measuring excess mortality during the COVID-19 pandemic in low- and lower-middle income countries: the need for mobile phone surveys ${ }^{1}$
}

Vissého Adjiwanou, Université du Québec à Montréal, Montréal (Canada)

Nurul Alam, icddr,b, Dhaka (Bangladesh)

Leontine Alkema, University of Massachusetts, Amherst (USA)

Gershim Asiki, Africa Population Health Research Center, Nairobi (Kenya)

Ayaga Bawah, University of Ghana, Accra (Ghana)

Donatien Béguy, UN Habitat, Nairobi (Kenya).

Valeria Cetorelli, UNRWA, Amman (Jordan)

Albert Dube, Malawi Epidemiology and Intervention research Unit, Chilumba (Malawi)

Dennis Feehan, University of California, Berkeley (USA).

Ane Bærent Fisker, Bandim Health Project (Denmark/Guinea-Bissau)

Anastasia Gage, Tulane University, New Orleans (USA)

Jenny Garcia, Institut National d'Etudes Démographiques, Paris (France)

Patrick Gerland, United Nations Population Division, New York (USA)

Michel Guillot, University of Pennsylvania, Philadelphia (USA), and Institut National d'Etudes

Démographiques, Paris (France)

Aashish Gupta, University of Pennsylvania, Philadelphia (USA)

Moinuddin Haider, iccdr,b, Dhaka (Bangladesh)

Stéphane Helleringer*, Johns Hopkins University, Baltimore (USA)

Momodou Jasseh, MRC Unit - The Gambia at LSHTM, Fajara (The Gambia)

Chodziwadziwa Kabudula, University of the Witwatersrand, Agincourt (South Africa)

Thomas LeGrand, Université de Montréal, Montréal (Canada)

Bruno Masquelier, Université Catholique de Louvain, Louvain-La-Neuve (Belgium)

Ashira Menashe-Oren, Université Catholique de Louvain, Louvain-La-Neuve (Belgium)

Tom Moultrie, University of Cape Town, Cape Town (South Africa)

Bernardo Lanza Queiroz, CEDEPLAR, Universidade Federal De Minas Gerais, Belo Horizonte

(Brazil)

Georges Reniers*, London School of Hygiene and Tropical Medicine, London (UK)

Abdramane Soura, Institut Supérieur des Sciences de la Population, University of

Ouagadougou, Ouagadougou (Burkina-Faso)

lan M. Timæus, London School of Hygiene and Tropical Medicine, London (UK)

Danzhen You, UNICEF, New York (USA)

${ }^{1}$ The views expressed in this paper are those of the authors and do not necessarily reflect the views of the United Nations and its agencies.

*Address all correspondence to Stéphane Helleringer (heller7@jhu.edu) or Georges Reniers (Georges.Reniers@Ishtm.ac.uk) 
Summary box :

- In low- and lower-middle income countries, data from civil registration systems do not allow monitoring excess mortality during the COVID-19 pandemic.

- Rapid mobile phone surveys aimed at measuring mortality trends on a monthly basis are a realistic and safe option for filling that data gap.

- The data generated by mobile phone surveys can play a key role in better targeting areas or population groups most affected by the pandemic.

- They can also help monitor the impact of interventions and programmes, and rapidly identify what works in mitigating the impact of COVID-19. 
Monitoring mortality is an essential component of an effective response to the COVID-19

pandemic. COVID-19 surveillance systems around the world count primarily deaths occurring in hospitals to individuals who tested positive to SARS-CoV-2, although some countries now also include deaths among suspected COVID-19 cases or that have occurred outside of hospitals. Surveillance systems do not count deaths from non-COVID-19 causes, even though they might spike due to health system disruption or downstream effects on the economy.

In high-income countries, civil registration and vital statistics (CRVS) systems remedy this undercount, after short delays. They register deaths from all causes, regardless of place of occurrence (1). This allows calculating "excess mortality", i.e., how many more deaths from any causes there are, compared to a recent pre-COVID-19 past. This measure is not affected by testing coverage or case-definition (2). It also includes the indirect effects of COVID-19 on deaths from other causes and is well-suited for comparing the impact of the pandemic on mortality over time, and between regions or countries.

In low and lower-middle income countries (LLMICs), surveillance systems also undercount the number of deaths due to COVID-19, but CRVS systems are insufficiently complete to fill the data gaps (1). Instead, researchers often use models to assess what effects an epidemic might have on mortality in LLMICs. Reduced healthcare utilization during the COVID-19 pandemic could thus have large effects on maternal and child health (3), or HIVIAIDS mortality (4). Model predictions can, however, seldom be assessed against empirical mortality data.

Over the next decade(s), reaching universal death registration will be essential for strengthening the response to pandemics in LLMICs (5). In the short term, interim tools are needed to assess excess mortality due to COVID-19. The surveys and censuses that constitute the primary source of mortality data in most LLMICs (6) are too infrequent for that purpose. These in-person 
inquiries also pose significant health risks in the context of COVID-19 as they involve group meetings, face-to-face interactions with thousands of respondents, and cross-country travel. Major survey programs and several censuses have suspended field activities indefinitely (7-9).

Mobile phone surveys (MPS) represent the most viable alternative approach to safely generating timely data on excess mortality. Owing to the penetration of mobile phones in all regions of the world, MPS have become highly popular in LLMICs. They can be conducted without in-person contact with respondents, which makes them particularly suitable for settings affected by epidemics or humanitarian crises (10). Few MPS, however, have measured mortality in LLMICs. We review several considerations in the planning of MPS aimed at measuring excess mortality during the COVID-19 pandemic. Decisions will vary between countries, due to differences in capacity to implement MPS or in the stage of the pandemic, for example.

How will participants be selected? Mortality MPS could select participants from lists of valid phone numbers obtained either from mobile operators (11), or from individuals enrolled in prior studies (12). These lists might allow selecting geographically targeted samples (e.g., cities). If lists of valid numbers are not available, surveyors might need to contact potential respondents using random digit dialing procedures (13). In some settings, MPS participants could also be sampled from registries of beneficiaries maintained by non-governmental or UN organizations, thus allowing to assess mortality among particularly vulnerable groups (e.g., refugees).

Which questions should be asked to measure excess mortality? Mortality MPS can build on standardized instruments used during in-person surveys and censuses (table 1). These include inquiries about recent deaths of household members, or about the survival of a respondent's relatives (e.g., parents, children or siblings). Data on household deaths allow 
estimating mortality over the entire age range, whereas questionnaires about respondents' relatives yield direct mortality estimates for specific age groups (14). Other instruments ask respondents to report deaths in their community (15) or social networks (16), but they have been used less often.

Interviews by mobile phone should remain short (20-30 minutes) to avoid interruptions due to network failure or respondent fatigue. This might limit the number of mortality questions that can be asked during MPS. Given that the risk of death from COVID-19 is concentrated in adult and older ages, mortality MPS might emphasize questions about respondents' parents (17). Since healthcare disruption during the pandemic might affect child survival (3), birth histories should be considered to detect indirect effects.

[TABLE 1 ABOUT HERE]

\section{Should mortality MPS include questions about the circumstances and causes of deaths?}

The extent of testing services for COVID-19 is limited in LLMICs, so few individuals will have been diagnosed with COVID-19 prior to death. In the absence of such data, MPS should include an assessment of co-morbidities and symptoms to evaluate the likelihood that the death is related to COVID-19. MPS should also include questions on care seeking before recent deaths, to identify barriers to testing and service utilization during the pandemic. Questions about the place of death (i.e., home vs. health facilities) would enable assessments of the completeness of data from surveillance systems. To reduce the burden on respondents, questions about symptoms and other circumstances surrounding reported deaths might be limited to events having occurred in a recent past. Finally, questions about the socioeconomic status of respondents and their deceased relatives should be asked. This information would allow 
exploring mortality differentials, and it might help adjust some of the sampling biases that affect MPS data.

How should mortality MPS be administered? Mortality questions are often sensitive to ask, for example when respondents are still grieving a recent death. The information about ages and dates requested in mortality questionnaires can also be complicated to obtain and record (e.g., time since a death). Mortality MPS should thus preferably be conducted by trained interviewers, rather than by SMS or interactive voice response (10). If needed due to restrictions on interactions, MPS interviewers can be trained remotely using video communication applications. Mortality MPS should also provide respondents information on local resources for grief counseling and psychosocial support.

How large and how frequent should mortality MPS be? To help inform pandemic response, cross-sectional MPS must be conducted frequently, e.g., every month. The required sample size of each MPS depends on i) pre-pandemic mortality levels, ii) expected excess mortality during the COVID-19 pandemic, iii) local socio-demographic factors (e.g., household size), and iv) the extent of data disaggregation required (e.g., whether we seek sub-national estimates). Experience from Europe and Latin America indicates that at country level (18), mortality might exceed pre-pandemic levels by $50-90 \%$ over at least one month. In LLMICs, excess mortality might be lower due to younger population structures (19), but other factors (e.g., prevalence of tuberculosis or cardiovascular diseases) might counteract this protective effect. Simulations calibrated to match local contexts should inform sample size calculations.

Even in settings with widespread disease transmission, deaths remain a rare (statistical) event. An MPS of $\approx 900$ respondents during the Ebola outbreak in Liberia yielded only 55 reports of deaths over the prior 10 months (11), a sample size insufficient to investigate excess mortality. 
Mortality MPS will require recruiting samples of several thousands of respondents, particularly in order to measure excess mortality at sub-national levels. Pooling data from multiple crosssectional MPS conducted over several months could enhance the statistical power available to detect differences in excess mortality between population groups (e.g., by gender). Networkbased data collection methods might achieve higher statistical power with smaller samples (16).

Where will the pre-COVID-19 mortality baseline come from? Most of the potential modules for a mortality MPS (Appendix A1) provide information on deaths and person-years that occurred over a sufficiently long period in the past to also estimate mortality rates prior to the pandemic. We recommend obtaining the pre-COVID-19 mortality baseline directly from MPS data. This will require asking respondents to report the month of a death to a) accurately classify deaths as having occurred before or during the COVID-19 pandemic, and b) account for seasonal variation in mortality. Internal consistency checks should be applied to verify that this baseline is not affected by date displacement and other respondent errors (20).

Limitations. The mortality data collected by MPS will display errors and biases similar to those encountered during in-person surveys. For example, families with low mortality might be overrepresented in the MPS sample due to survivor bias (21). Estimating relative increases in mortality during the COVID-19 pandemic, and comparing these estimates across countries, will require statistical models that might at times yield discrepant estimates (22).

Inferring the number of excess deaths in a population from MPS data will present further challenges. MPS often have high nonresponse rates. This can only be partially remedied by giving airtime incentives to respondents (23), or through sensitization campaigns led by ministries of health or UN organizations. Participation in MPS is also selective, e.g., because some impoverished areas of LLMICs have imperfect mobile network coverage. MPS samples 
thus often over-represent younger, urban and more affluent populations (24). Statistical modeling can at least partially account for some of these sampling and reporting biases. Sensitivity analyses can help further mitigate the limitations of MPS, by evaluating mortality trends and differentials under varying assumptions.

Conclusion. Countries with limited CRVS systems lack information to monitor the effects of COVID-19 on mortality. MPS have the potential to provide such information and thus inform interventions and programs. Since their costs $(10,13)$ are limited, frequent mortality MPS should be included in plans to respond to the pandemic in LLMICs. National or cross-country MPS currently being rolled-out to monitor other indicators (e.g., poverty) should also consider adding a mortality module to their instruments. 


\section{REFERENCES:}

1. Mikkelsen L, Phillips DE, AbouZahr C, Setel PW, de Savigny D, Lozano R, et al. A global assessment of civil registration and vital statistics systems: monitoring data quality and progress. Lancet. 2015 Oct 3;386(10001):1395-406.

2. Leon DA, Shkolnikov VM, Smeeth L, Magnus P, Pechholdová M, Jarvis CI. COVID-19: a need for real-time monitoring of weekly excess deaths. The Lancet. 2020 May 2;395(10234):e81.

3. Roberton T, Carter ED, Chou VB, Stegmuller A, Jackson BD, Tam Y, et al. Early Estimates of the Indirect Effects of the Coronavirus Pandemic on Maternal and Child Mortality in Lowand Middle-Income Countries [Internet]. Rochester, NY: Social Science Research Network; 2020 Apr [cited 2020 May 2]. Report No.: ID 3576549. Available from:

https://papers.ssrn.com/abstract=3576549

4. Hogan A, Jewell B, Sherrard-Smith E, Vesga J, Watson O, Whittaker C, et al. Report 19: The potential impact of the COVID-19 epidemic on HIV, TB and malaria in low- and middle-income countries [Internet]. 29. 2020 May [cited 2020 May 12]. Available from: http://spiral.imperial.ac.uk/handle/10044/1/78670

5. Shibuya K, Gilmour S. Civil registration as a means to promote human security. The Lancet. 2015 Oct 3;386(10001):e14-5.

6. Reniers G, Masquelier B, Gerland P. Adult Mortality in Africa. In: Rogers RG, Crimmins EM, editors. International Handbook of Adult Mortality [Internet]. Dordrecht: Springer Netherlands; 2011 [cited 2019 Dec 23]. p. 151-70. (International Handbooks of Population). Available from: https://doi.org/10.1007/978-90-481-9996-9_7

7. COVID-19 PANDEMIC AND IMPLEMENTATION OF MULTIPLE INDICATOR CLUSTER SURVEYS (MICS) - UNICEF MICS [Internet]. [cited 2020 Apr 25]. Available from: https://mics.unicef.org/news_entries/157/COVID-19-PANDEMIC-ANDIMPLEMENTATION-OF-MULTIPLE-INDICATOR-CLUSTER-SURVEYS-(MICS)

8. The DHS Program - COVID-19 Response: DHS Program Fieldwork Activities on Hold [Internet]. [cited 2020 May 7]. Available from: https://dhsprogram.com/Who-We-Are/NewsRoom/COVID-19-Response-DHS-Program-Fieldwork-Activities-on-Hold.cfm

9. How COVID-19 is changing the world: A statistical perspective [Internet]. UNICEF DATA. 2020 [cited 2020 May 18]. Available from: https://data.unicef.org/resources/how-covid-19is-changing-the-world-a-statistical-perspective/

10. Dabalen A, Etang A, Hoogeveen J, Mushi E, Schipper Y, von Engelhardt J. Mobile phone panel surveys in developing countries: a practical guide for microdata collection. The World Bank; 2016.

11. Kuehne A, Lynch E, Marshall E, Tiffany A, Alley I, Bawo L, et al. Mortality, Morbidity and Health-Seeking Behaviour during the Ebola Epidemic 2014-2015 in Monrovia Results from a Mobile Phone Survey. PLoS Negl Trop Dis. 2016;10(8):e0004899. 
12. COVID-19 DATA FROM BELIZE MICS PLUS PILOT - UNICEF MICS [Internet]. [cited 2020 May 8]. Available from: http://mics.unicef.org/news_entries/159/COVID-19-DATAFROM-BELIZE-MICS-PLUS-PILOT

13. L'Engle K, Sefa E, Adimazoya EA, Yartey E, Lenzi R, Tarpo C, et al. Survey research with a random digit dial national mobile phone sample in Ghana: Methods and sample quality. PLoS ONE. 2018;13(1):e0190902.

14. Timaeus IM, Jasseh M. Adult mortality in sub-Saharan Africa: evidence from Demographic and Health Surveys. Demography. 2004 Nov;41(4):757-72.

15. Alam N, Townend J. The Neighbourhood Method for Measuring Differences in Maternal Mortality, Infant Mortality and Other Rare Demographic Events. PLOS ONE. 2014 Jan 2;9(1):e83590.

16. Feehan DM, Mahy M, Salganik MJ. The Network Survival Method for Estimating Adult Mortality: Evidence From a Survey Experiment in Rwanda. Demography. 2017 Aug 1;54(4):1503-28.

17. Hirschman C, Preston S, Loi VM. Vietnamese Casualties During the American War: A New Estimate. Population and Development Review. 1995;21(4):783-812.

18. Deaths registered weekly in England and Wales, provisional - Office for National Statistics [Internet]. [cited 2020 Apr 25]. Available from:

https://www.ons.gov.uk/peoplepopulationandcommunity/birthsdeathsandmarriages/deaths/ bulletins/deathsregisteredweeklyinenglandandwalesprovisional/weekending10april2020\#d eaths-registered-by-week

19. Dowd JB, Andriano L, Brazel DM, Rotondi V, Block P, Ding X, et al. Demographic science aids in understanding the spread and fatality rates of COVID-19. PNAS. 2020 May 5;117(18):9696-8.

20. Helleringer S, Pison G, Kanté AM, Duthé G, Andro A. Reporting Errors in Siblings' Survival Histories and Their Impact on Adult Mortality Estimates: Results From a Record Linkage Study in Senegal. Demography. 2014 Apr;51(2):387-411.

21. Masquelier B. Adult mortality from sibling survival data: a reappraisal of selection biases. Demography. 2013 Feb;50(1):207-28.

22. Alkema L, You D. Child Mortality Estimation: A Comparison of UN IGME and IHME Estimates of Levels and Trends in Under-Five Mortality Rates and Deaths. PLoS Med [Internet]. 2012 Aug 28 [cited 2020 May 18];9(8). Available from: https://www.ncbi.nlm.nih.gov/pmc/articles/PMC3429386/

23. Gibson DG, Wosu AC, Pariyo GW, Ahmed S, Ali J, Labrique AB, et al. Effect of airtime incentives on response and cooperation rates in non-communicable disease interactive voice response surveys: randomised controlled trials in Bangladesh and Uganda. BMJ Global Health. 2019 Sep 1;4(5):e001604. 
24. Lau CQ, Cronberg A, Marks L, Amaya A. In Search of the Optimal Mode for Mobile Phone Surveys in Developing Countries. A Comparison of IVR, SMS, and CATI in Nigeria. Survey Research Methods. 2019 Dec 10;13(3):305-18.

25. Akuze J, Blencowe H, Waiswa P, Baschieri A, Gordeev VS, Kwesiga D, et al. Randomised comparison of two household survey modules for measuring stillbirths and neonatal deaths in five countries: the Every Newborn-INDEPTH study. The Lancet Global Health. $2020 \mathrm{Apr}$ 1;8(4):e555-66. 


\begin{tabular}{|c|c|c|c|c|c|}
\hline & $\begin{array}{l}\text { Recent } \\
\text { Household } \\
\text { Deaths }\end{array}$ & $\begin{array}{l}\text { Parental } \\
\text { Survival } \\
\text { History }\end{array}$ & $\begin{array}{l}\text { Sibling } \\
\text { Survival } \\
\text { History }\end{array}$ & $\begin{array}{l}\text { Full } \\
\text { Birth } \\
\text { History }^{4}\end{array}$ & $\begin{array}{l}\text { Personal } \\
\text { network } \\
\text { members }\end{array}$ \\
\hline $\begin{array}{l}\text { Indicators typically } \\
\text { produced }\end{array}$ & $\begin{array}{l}\text { Crude death rate } \\
\text { Age-specific } \\
\text { mortality rates } \\
\text { PRMR }\end{array}$ & $\begin{array}{l}30 q 50 \\
20 q 60^{2}\end{array}$ & $\begin{array}{l}10 q 15 \\
35 q 15 \\
45 q 15 \\
\text { PRMR }\end{array}$ & $\begin{array}{l}\text { NMR, } \\
1 q 0 \\
4 q 1 \\
5 q 0 \\
10 q 5\end{array}$ & $\begin{array}{l}\text { Crude death rate } \\
\text { Age-specific } \\
\text { mortality rates }\end{array}$ \\
\hline Collected in & $\begin{array}{l}\text { Census and some } \\
\text { DHS }\end{array}$ & $\begin{array}{l}\text { Census } \\
\text { (w/o age data) } \\
\text { Ad hoc surveys }\end{array}$ & DHS/MICS & DHS/MICS & Ad hoc surveys \\
\hline Typical respondent & $\begin{array}{l}\text { Household } \\
\text { informant }\end{array}$ & $\begin{array}{l}\text { Woman } 15-49 y \\
\text { Man } 15-54 y\end{array}$ & $\begin{array}{l}\text { Woman } 15-49 y \\
\text { Man } 15-54 y\end{array}$ & Woman 15-49y & $\begin{array}{l}\text { Adult women or } \\
\text { men }\end{array}$ \\
\hline $\begin{array}{l}\text { Definition of } \\
\text { relative/relation }\end{array}$ & $\begin{array}{l}\text { Household } \\
\text { members }\end{array}$ & $\begin{array}{l}\text { Biological } \\
\text { mother/father }\end{array}$ & $\begin{array}{l}\text { Siblings born to } \\
\text { same biological } \\
\text { mother }\end{array}$ & $\begin{array}{l}\text { Own children born } \\
\text { alive }\end{array}$ & $\begin{array}{l}\text { Personal network } \\
\text { members }\end{array}$ \\
\hline $\begin{array}{l}\text { Questions about } \\
\text { surviving } \\
\text { relatives/relations }\end{array}$ & $\begin{array}{l}\text { Age } \\
\text { Sex }\end{array}$ & $\begin{array}{l}\text { Age } \\
\text { Sex }\end{array}$ & $\begin{array}{l}\text { Age } \\
\text { Sex }\end{array}$ & $\begin{array}{l}\text { Age } \\
\text { Sex } \\
\text { DOB } \\
\text { Residence }\end{array}$ & $\begin{array}{l}\text { Number of } \\
\text { connections to } \\
\text { subgroups of } \\
\text { known size }\end{array}$ \\
\hline $\begin{array}{l}\text { Questions about } \\
\text { deceased } \\
\text { relatives/relations }\end{array}$ & $\begin{array}{l}\text { Age at death } \\
\text { Sex } \\
\text { Time since death }\end{array}$ & $\begin{array}{l}\text { Age at death } \\
\text { Sex (implicit) } \\
\text { Time since death }\end{array}$ & $\begin{array}{l}\text { Age at death } \\
\text { Sex } \\
\text { Time since death }\end{array}$ & $\begin{array}{l}\text { Age at death } \\
\text { Sex }\end{array}$ & $\begin{array}{l}\text { Age at death } \\
\text { Sex } \\
\text { Time since death }\end{array}$ \\
\hline $\begin{array}{l}\text { Questions about } \\
\text { circumstances of } \\
\text { reported deaths }\end{array}$ & $\begin{array}{l}\text { Pregnancy-related } \\
\text { deaths } \\
\text { External deaths }\end{array}$ & $\begin{array}{l}\text { Pregnancy-related } \\
\text { deaths } \\
\text { External deaths }\end{array}$ & $\begin{array}{l}\text { Pregnancy-related } \\
\text { deaths } \\
\text { External deaths }\end{array}$ & $\mathrm{N} / \mathrm{A}$ & $\mathrm{N} / \mathrm{A}$ \\
\hline $\begin{array}{l}\text { Additional data } \\
\text { required to produce } \\
\text { estimates? }\end{array}$ & $\begin{array}{l}\text { No, numerator \& } \\
\text { denominator } \\
\text { generated from } \\
\text { MPS }\end{array}$ & $\begin{array}{l}\text { No, numerator \& } \\
\text { denominator } \\
\text { generated from } \\
\text { MPS }\end{array}$ & $\begin{array}{l}\text { No, numerator \& } \\
\text { denominator } \\
\text { generated from } \\
\text { MPS }\end{array}$ & $\begin{array}{l}\text { No, numerator \& } \\
\text { denominator } \\
\text { generated from } \\
\text { MPS }\end{array}$ & $\begin{array}{l}\text { Yes, data from } \\
\text { census or } \\
\text { registries about } \\
\text { various groups }\end{array}$ \\
\hline $\begin{array}{l}\text { Time required to } \\
\text { complete module }\end{array}$ & $\begin{array}{l}\approx 4-5 \text { mins } \\
(\text { Brazil })^{1}, \\
\approx 10 \text { mins }(\text { RSA })^{1}\end{array}$ & $<3$ mins $^{3}$ & $\approx 8 \mathrm{mins}^{3}$ & $\approx 9$ mins $^{5}$ & $\approx 8-10 \mathrm{mins}^{6}$ \\
\hline
\end{tabular}

Table 1: Characteristics of interview modules available to measure mortality in MPS 
Abbreviations and definitions:

$30 q 50=$ probability of dying between ages 50 and 80 years old

$20 \mathrm{q} 60=$ probability of dying between ages 60 and 80 years old

$10 q 15=$ probability of dying between ages 15 and 25 years old

$35 q 15=$ probability of dying between ages 15 and 50 years old

$45 q 15=$ probability of dying between ages 15 and 60 years old

$1 \mathrm{q} 0=$ probability of dying between birth and age 1 (infant mortality rate)

$4 q 1=$ probability of dying between ages 1 and 5 years old

$5 \mathrm{q} 0=$ probability of dying between birth and 5

$10 \mathrm{q} 5=$ probability of dying between ages 5 and 15 years old

$\mathrm{DOB}=$ Date of birth

PRMR = Pregnancy-related mortality ratio

RSA = Republic of South Africa

$\mathrm{N} / \mathrm{A}=$ Not applicable

Notes:

${ }^{1}$ From national census data collection in 2010 (Brazil) and 2011 (Republic of South Africa).

${ }^{2}$ In countries with early patterns of childbearing, data on parental survival could be used to generate estimates of mortality from age 40.

${ }^{3}$ From study in Malawi (Dube et al., Working Paper)

${ }^{4}$ The DHS recently adopted full pregnancy histories, in which respondents are asked to list all the pregnancies they have ever had and to state their outcomes.

${ }^{5}$ From multi-country ENAP study (see reference 25 ).

${ }^{6}$ Estimate based on previous network scale-up studies (e.g. reference 15). 


\section{Appendix A1: Approaches to measuring excess mortality using MPS}

This appendix provides additional detail on five approaches used to measure mortality through surveys (table 1). It identifies changes that would be required prior to integrating these instruments into MPS. Each of the approaches listed below can yield estimates for different population sub-groups and require different sample sizes.

\section{1- Recent household deaths}

Measuring mortality from information on recent (up to 24 months) household deaths is based on (1) enumerating all resident household members at the time of the survey in a household roster, (2) collecting information on their age and sex, and (3) enumerating deaths in the recent past (including information on age at death). These questions are regularly added to national census questionnaires, usually for deaths occurring in the last 12 months. In order to measure changes in mortality over a shorter period of time to detect possible excess mortality related to the pandemic, the following list of questions may be considered:

\begin{tabular}{|c|c|c|c|c|c|}
\hline NO. & \multicolumn{2}{|c|}{ QUESTIONS AND FILTERS } & \multicolumn{2}{|c|}{ CODING CATEGORIES } & SKIP \\
\hline & \multicolumn{4}{|c|}{ Now I would like to ask you a few more questions about your household } & \\
\hline $\mathrm{HH} 1$ & \multicolumn{2}{|c|}{$\begin{array}{l}\text { Think back over the past } 2 \text { years. Has any usual member of } \\
\text { your household died in the last } 2 \text { years? }\end{array}$} & \multicolumn{2}{|c|}{ 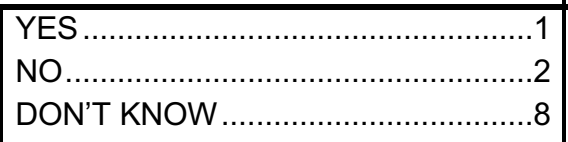 } & $\begin{array}{l}\rightarrow \text { END } \\
\rightarrow \text { END }\end{array}$ \\
\hline $\mathrm{HH} 2$ & \multicolumn{2}{|c|}{ How many household members died in the last 2 years? } & \multicolumn{2}{|c|}{ NUMBER OF DEATHS ......... } & \\
\hline $\mathrm{HH} 3$ & $\begin{array}{l}\text { What was the name of the person who } \\
\text { died (most recently/before him/her)? }\end{array}$ & $\begin{array}{l}\text { NAME OF } 1^{\text {ST }} \\
\text { DEATH }\end{array}$ & $\begin{array}{l}\text { NAME OF } 2^{\text {ND }} \\
\text { DEATH }\end{array}$ & $\begin{array}{l}\text { NAME OF } 3^{\text {RD }} \\
\text { DEATH }\end{array}$ & \\
\hline $\mathrm{HH} 4$ & Was (NAME) male or female? & $\begin{array}{l}\text { MALE } \ldots \ldots \ldots \ldots \ldots . .1 \\
\text { FEMALE } \ldots \ldots \ldots \ldots . . .2\end{array}$ & $\begin{array}{l}\text { MALE } \ldots \ldots \ldots \ldots \ldots . .1 \\
\text { FEMALE } \ldots \ldots \ldots \ldots . . .2\end{array}$ & $\begin{array}{l}\text { MALE } \ldots \ldots \ldots \ldots \ldots . . .1 \\
\text { FEMALE } \ldots \ldots \ldots \ldots . . .2\end{array}$ & \\
\hline HH5 & $\begin{array}{l}\text { How old was (NAME) when (he/she) } \\
\text { died? }\end{array}$ & AGE $\ldots \ldots .$. & AGE ........ & AGE ....... & \\
\hline$\overline{\mathrm{HH} 6}$ & What was the date of death of (NAME)? & $\begin{array}{l}\text { MONTH: } \\
\text { YEAR: }\end{array}$ & $\begin{array}{l}\text { MONTH: } \\
\text { YEAR: }\end{array}$ & $\begin{array}{l}\text { MONTH: } \\
\text { YEAR: }\end{array}$ & \\
\hline
\end{tabular}

This sample questionnaire is based on a module entitled 'Support for people who have died' that has been included in some Demographic and Health Surveys (DHS) and has been used to estimate mortality in older adults (Bendavid et al., 2011). A reference period longer than the last 12 months is desirable in order to measure baseline mortality accurately, taking into account seasonality. Extending the reference period beyond 2 or 3 years may, however, aggravate biases in the estimates due, for example, to reporting errors (omissions, errors on ages at death) or selection biases (dissolution of some households following the death of one of the members). 
Age-specific mortality rates are calculated by dividing deaths in each age category and for each separate sex by the population counts obtained from the household roster. Since the reference period for reporting deaths precedes the enumeration of the household members, populations at risk are obtained by reducing the enumerated population based on an assumed rate of population growth. This procedure avoids the need to collect additional information on departures from the household or new members arriving during the reference period.

\section{2- Sibling survival histories}

Sibling histories are collected on a regular basis in DHS, where each woman aged 15-49 years is asked to list her siblings born to the same mother. Women report on the sex and survival of each sibling, their ages at the time of the survey for surviving siblings, or their ages at death and the timing of death for those who died. These data are regularly used to calculate all-cause adult mortality. The full questionnaire used by the DHS is available here: https://dhsprogram.com/pubs/pdf/DHSQM/DHS8-Module-Adult-Maternal-Mort-EN30Apr2020-DHSQM.pdf.

Sibling histories were not developed to measure short-term variations in mortality. The timing of death is usually only collected in terms of years elapsed since death, and imputation procedures are then used to allocate to each sibling a date of birth and a possible date of death, expressed in months. To detect possible excess mortality related to the COVID-19 pandemic, more detail should be obtained on the timing of deaths. Question MM17 could be replaced by the following:

\begin{tabular}{|l|l|c|}
\hline MM17 & $\begin{array}{l}\text { How many years ago did (NAME OF SIBLING) } \\
\text { die? }\end{array}$ & Number of years: \\
\hline
\end{tabular}

\begin{tabular}{|c|l|l|}
\hline MM & In what year did (NAME OF SIBLING) die? & Year: \\
17 & \multicolumn{2}{|l}{} \\
\hline MM & Check MM17: \\
$17-2$ & $\begin{array}{l}\text { IF }<2019, \text { THEN GO TO NEXT SIBLING } \\
\text { IF }>=2019, \text { THEN ASK MM17-3 }\end{array}$ \\
\hline MM & In what month did ( NAME OF SIBLING) die? & Month: \\
$17-3$ & & \\
\hline
\end{tabular}

Sibling histories are useful for measuring mortality from 15 to 50 years of age, sometimes up to 60 years of age. They are not suitable for mortality beyond age 60 because the questions are usually asked of respondents aged 15-49. Since respondents are generally the same age on average as their siblings, the number of deaths and person-years of exposure decreases rapidly with age when estimating mortality beyond the age of 50 .

Sibling survival histories are relatively time-consuming and repetitive to collect. They could therefore lead to respondent fatigue when administered in MPS. An alternative approach is to ask questions only about the number of siblings who survived to age 15 , and the number of surviving siblings at the time of the survey, which greatly shortens the questionnaire, but only allows an indirect calculation of mortality, assuming that the respondents are approximately the same age as their siblings (Timæus et al., 2001). However, this method is not suitable for measuring changes in mortality in the short term. Another indirect approach might ask respondents about their siblings who are still alive at the time of interview, and about their siblings who have died in the last two years (specifying whether they occurred before or after the COVID-19 pandemic). This approach is worth exploring to simplify data collection but would require further research and validation. 


\section{3- Full birth or pregnancy histories}

Mortality estimates of children aged 0-14 years old can be derived from full birth or pregnancy histories, which contain a series of detailed questions on each child a woman has given birth to during her lifetime, or each pregnancy, including live births, stillbirths, miscarriages and abortions in the case of pregnancy histories. Full pregnancy histories are now part of the core DHS questionnaire (Section 2. Reproduction), available here: https://dhsprogram.com/pubs/pdf/DHSQ8/DHS8 Womans QRE EN 8Apr2020 DHSQ8.pdf

This module collects information on the date of birth of children born alive, and their age at death, in days for neonatal deaths, in months for deaths under two years of age, and in years thereafter. For deaths under 2 years of age, it is therefore possible to pinpoint the date of death to the nearest month, provided that this information is known to the respondent. However, for deaths occurring among children above age 2, it would be more difficult to locate the death in relation to the pandemic. For use in COVID-19 mortality monitoring, our suggestion would be to add a question about year of birth for all children, in order to identify deaths that occurred in 2020 or before. Then, for and for those deaths that occurred in 2020 , add a question on the month of death.

Some DHS surveys have included truncated birth histories, in which information is collected only on the last 3 or 5 births, or births within the last 3 or 5 years. Truncated birth histories have the advantage of reducing the length of the interview and could be considered for MPS to reduce costs and respondent fatigue. Experience with birth histories truncated to a specific reference period in non-crisis contexts suggests they are associated with lower quality data (Hill, 2011) when interviewers have an interest in shifting some births out of the reference period to save time, for example to avoid additional questions asked about breastfeeding, immunization or other health outcomes for the most recent births in a typical DHS. The frequency of birth transfers is likely to be lower if these additional questions are not asked in MPS. Yet care should be taken not to reduce the reference period too much, because the under-five mortality rate in the last 2 to 3 years is partly estimated from children born more than 2 to 3 years ago. Ideally, information on children born in the last 5-10 years should be collected to allow calculating under-five mortality in the relatively recent past.

\section{4- Parental survival histories}

Parental survival histories (PSH) are a survey method for the collection of data on mortality at older ages (Hirschman et al., 1995). In PSH, respondents are asked 1) whether each of their biological parents is still alive, 2) how old they are in completed years (surviving parent), and/or 3) how old they were when they died and when the death occurred (deceased parent). Based on these data, age-specific death rates can be calculated, by dividing the number of reported deaths in an age group (e.g., 60-64 years old) by the number of personyears lived in that age group. PSH are an extension of sibling and birth histories. PSH also extend data on orphanhood among young children, which have frequently been collected in surveys and censuses since the 1960's, but usually without questions on ages of parents and the timing of their death (Timæus and Jasseh, 2004). PSH are particularly appealing for monitoring COVID-19 mortality through MPS because they require very limited time to collect and produce mortality estimates for the age range in which individuals are most at risk $(40+)$.

The following questions may be asked about the biological mother and biological father of each respondent: 


\begin{tabular}{|c|c|c|c|}
\hline No. & QUESTIONS AND FILTERS & CODING CATEGORIES & SKIP \\
\hline PS1 & What is the name of your biological mother? & Name: & \\
\hline PS2 & Is your biological mother still alive? & 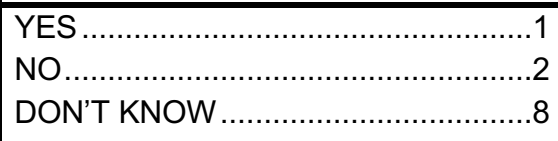 & $\begin{array}{l}\rightarrow \text {PPS4} 4 \\
\rightarrow \text { END }\end{array}$ \\
\hline PS3 & $\begin{array}{l}\text { How old is she? } \\
\text { RECORD AGE IN COMPLETED YEARS }\end{array}$ & 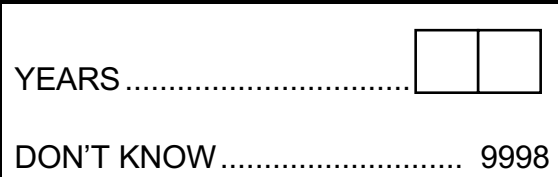 & \\
\hline PS4 & How old was your biological mother when she died? & 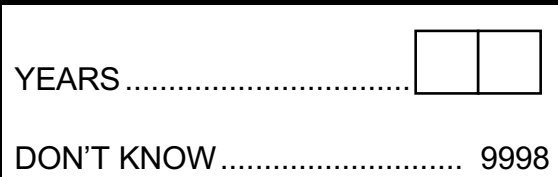 & \\
\hline PS5 & In what year did she die? & 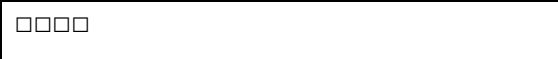 & \\
\hline PS6 & \begin{tabular}{|l|} 
Check MM17: \\
IF < 2019, THEN GO TO QUESTIONS ON FATHER \\
IF >= 2019, THEN ASK PS7
\end{tabular} & & \\
\hline PS7 & In what month of the year did she die? & 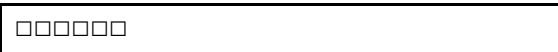 & \\
\hline
\end{tabular}

\section{5- Personal network reports}

The network survival method can be used to estimate death rates by collecting information about people who died, and people who did not die, in respondents' personal networks. The approach was designed to take the idea behind the sibling survival method and to generalize it to work with relationships other than sibship; it is closely related to the network scale-up method (Feehan and Salganik, 2016).

In principle, network survival estimates could be made from information collected about many different types of relationship - for example, friends, neighbors, various kin relations, work colleagues, etc. However, the method is new and only two relationships have been empirically tested: people the respondent reports 'knowing', and people the respondent reports having shared a meal with (Feehan et al, 2017).

For a given relationship, three types of information must be collected to produce death rate estimates. First, the respondent's own age and sex must be collected. Second, the respondent is asked to report about her connections to different groups of known size. For example, here are two questions from a study in Rwanda (this study used the 'know' definition of a personal network): 


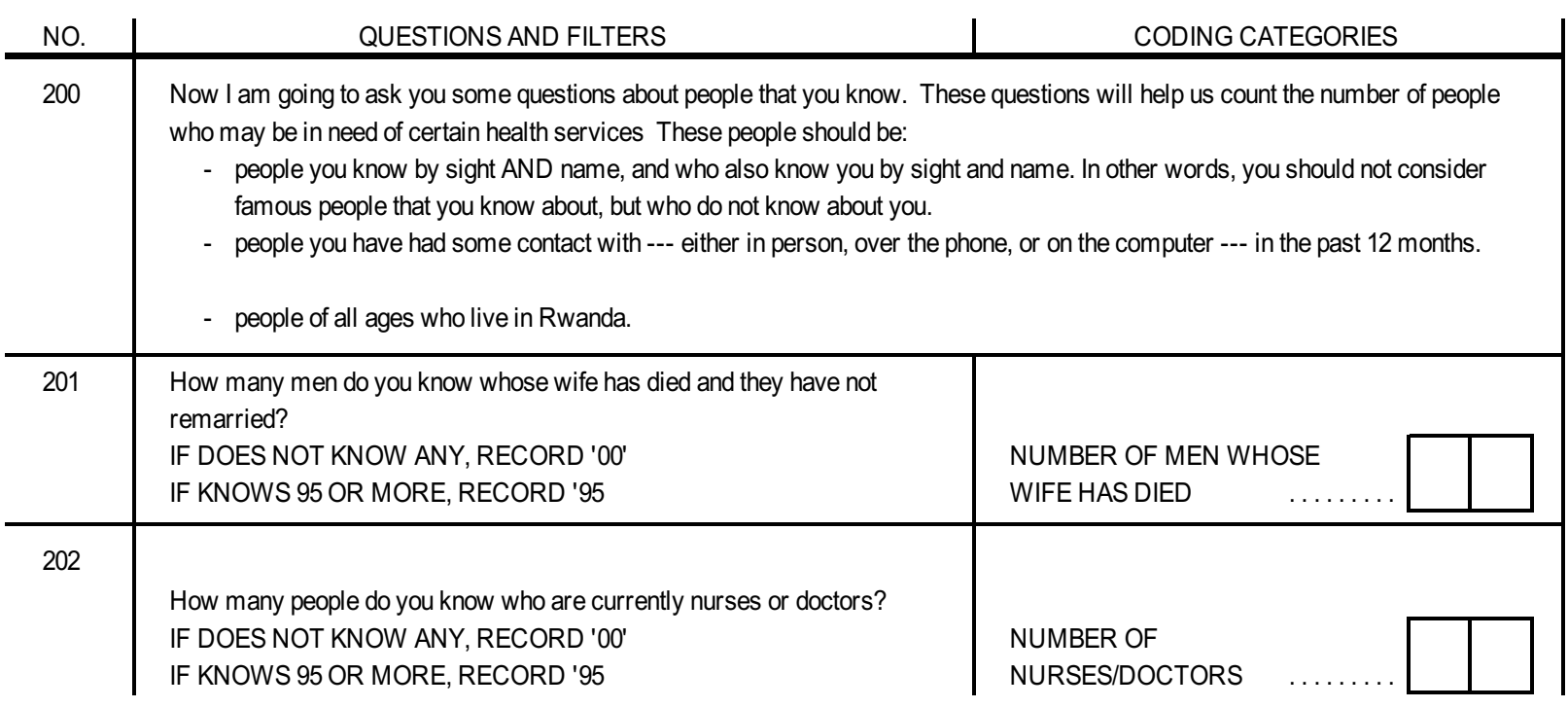

The idea is that respondents with bigger personal networks will tend to report more connections to these groups. It is best to ask respondents about their connections to many groups (at least ten). The total size of these groups must be known, perhaps from a census or from administrative records. In principle, if the relationship is such that respondents could directly report the size of their personal networks, then the need for these questions could be eliminated; however, this has not previously been tested.

Third, the respondent is asked to report in more detail about people in her network who have died. The deaths do not have to be from among the specific groups listed before. Continuing the example from Rwanda:

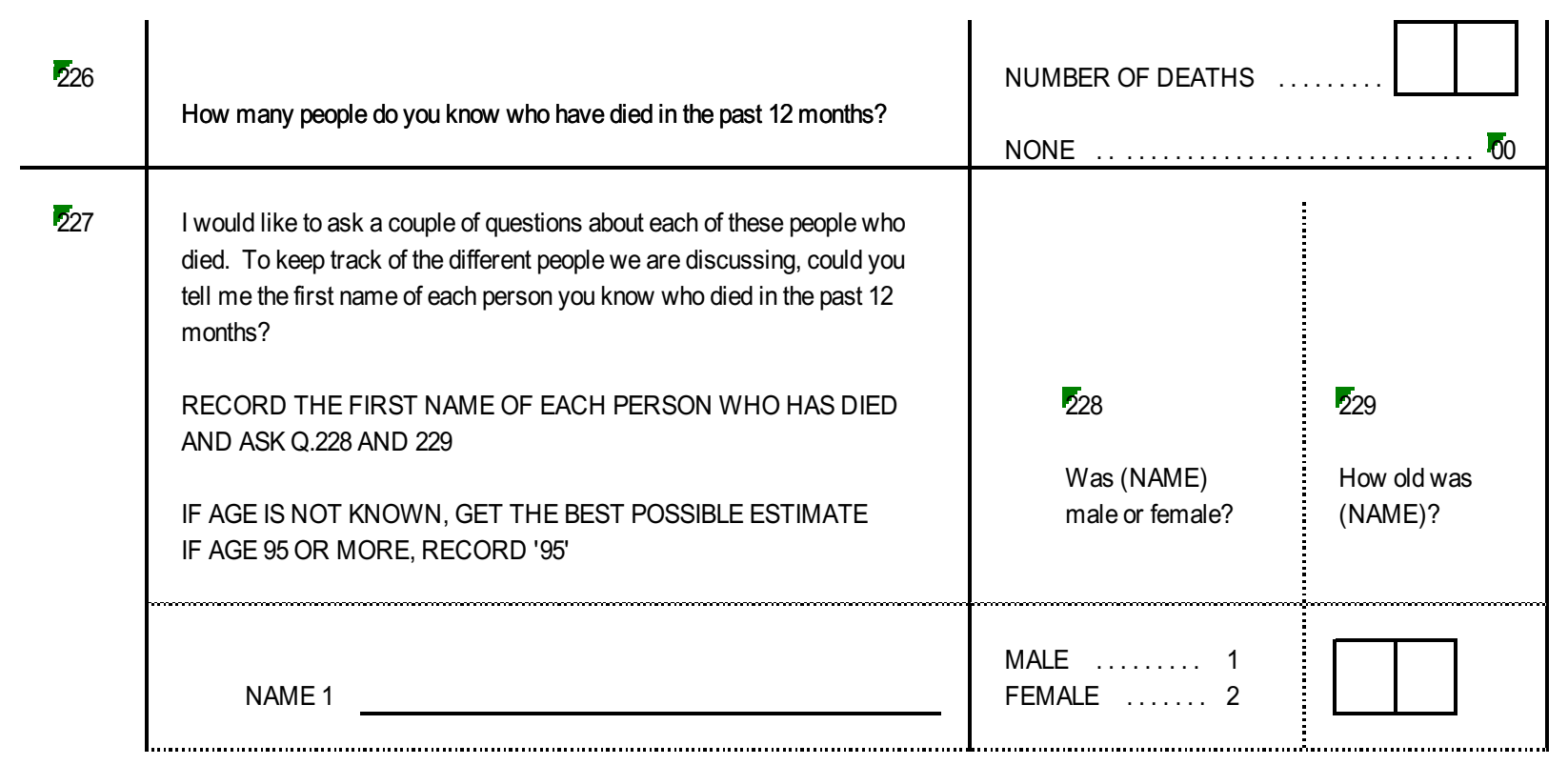

The instrument in Rwanda collected information about up to 12 specific people who died; in other contexts, allowing respondents to report about more or fewer deaths may be appropriate. There are two potential advantages to the network survival method: first, it can be customized to work for relationships that make the most sense in a given context. Second, it provides an opportunity to learn about a relatively large number of deaths from each interview. For example, the Rwanda study estimated that using the 'know' relationship, respondents reported about 80 times more deaths in the 12 months before the interview than were produced from questions about siblings. 
However, the method is new, so there is relatively little field experience applying it. For example, the method relies on respondents' reports about their personal network members being accurate, on average. There is not currently empirical evidence to understand which types of relationship produce the most accurate reports.

The network method has not previously been used to estimate excess mortality. However, it may be possible to do so by (1) modifying the questions about deaths so that respondents are asked to report about deaths over the 24 months before the interview, and (2) for each reported death, asking how long before the interview the person died.

\section{References}

Bendavid, E.; Seligman, B. \& Kubo, J., Comparative Analysis of Old-Age Mortality Estimations in Africa, PLoS ONE, 2011, 6, e26607

Feehan, D. \& Salganik M.J. Generalizing the network scale-up method: a new estimator for the size of hidden populations, Sociological Methodology 46, no. 1, 2016, 153-186

Helleringer, S.; Pison, G.; Masquelier, B.; Kanté, A.; Douillot, L.; Duthé, G.; Sokhna, C. \& Delaunay, V., Improving the Quality of Adult Mortality Data Collected in Demographic Surveys: Validation Study of a New Siblings' Survival Questionnaire in Niakhar, Senegal, PLoS Medicine, 2014, 11, e1001652

Hill, K., "Direct estimation of child mortality from birth histories", in Moultrie, T.; Dorrington, R.; Hill, A.; Hill, K.; Timæus, I. \& Zaba, Z. (Eds.), Tools for Demographic Estimation, International Union for the Scientific Study of Population, Paris, 2013

Hirschman, C.; Preston, S. \& Loi, V. M. Vietnamese Casualties During the American War: A New Estimate Population and Development Review, 1995, 21, pp. 783-812

Timæus, I.; Zaba, B. \& Ali, M. "Estimation of adult mortality from data on adult siblings", in Zaba, B. \& Blacker, J. (Eds.) Brass Tacks: Essays in Medical Demography, Athlone Press, London, 2001, 43-66

Timæus, I. M. \& Jasseh, M., Adult mortality in Sub-Saharan Africa: evidence from demographic and health surveys, Demography, 2004, 41, 4, 757-772 